\title{
LA CONGRUENCIA DE LA SENTENCIA EN EL PROCESO CIVIL ROMANO
}

\author{
María Olga Gil García \\ Universidad de Burgos, Espanha \\ ogil@ubu.es
}

RESUMEN: En este estudio situamos el origen de la congruencia de la sentencia en los procedimientos de Derecho romano, el ordo iudiciorum privatorum, y la cognitio extra ordinem, y sus parecidos con el concepto vigente, señalando especialmente las consecuencias de la sentencia incongruente para el juzgador y la aplicación o no del cuasidelito litem suam facere.

PALABRAS CLAVE: Congruencia. litem suam facere. iurare sibi non liquere. Responsabilidad del juez.

\section{The consistency (congruence) of the judgement in roman civil-law procedure}

\begin{abstract}
In this study, we situate the origin of the consistency (congruence) of the judgement in the procedures of Roman Law, ordo iudiciorum privatorum, and cognitio extra ordinem, and their similarities with the current concept, pointing especially to the consequences of the inconsistent judgement for the courts and the application or otherwise of the quasi-offense litem suam facere.
\end{abstract}

KEYWORDS: Consistency (congruence), litem suam facere, iurare sibi non liquere, responsibility of the court.

\section{A congruência da sentença no processo civil romano}

RESUMO: este estudo, situamos a origem da congruência da sentença nos procedimentos de Direito Romano, o ordo iudiciorum privatorum, e a cognitio extra ordinem, e suas semelhanças com o conceito vigente, assinalando especialmente as consequências da sentença incongruente para o julgador e a aplicação ou não do quase-delito litem suam facere.

PALAVRAS-CHAVE: Congruência. Litem suam facere. Iurare sibi non liquere. Responsabilidade do juiz.

\section{INTRODUCCIÓN}

La congruencia procesal es un requisito interno de la sentencia que relaciona lo solicitado por las partes procesales en un pleito y lo que finalmente otorga el juez en su fallo. El objetivo de este estudio es ver como se ha ido conformando esta cualidad de la sentencia, desde prácticamente su inexistencia hasta su construcción doctrinal actual con base principalmente en el proceso romano. Para ello hemos utilizado las fuentes y observado como en la cognitio extra ordinem, ya se aplican criterios de incongruencia similares a los actuales. Hemos partido del concepto y de su reconocimiento implícito en los distintos sistemas procesales romanos, que llegan a aplicarla aún sin referir su nombre, incluyendo la diferente responsabilidad del juez ante una resolución incongruente, para seguir revisando su incorporación tanto en la Recepción como en la Codificación, finalizando con su anclaje en la Constitución española de 1978. 


\section{CONCEPTO}

La sentencia civil es el acto procesal por excelencia, aquél por el que el Derecho se hace vivo al aplicarse al caso concreto. Ese pronunciamiento será la consecuencia del razonamiento lógico y volitivo del juzgador. El juez debe estimar tanto los hechos como el derecho aplicable y, con todo ello, concluir cual será el fallo de su resolución. La correlación entre lo pedido por los actuantes y lo resuelto por el juez será la congruencia.

La doctrina romanista rara vez se refiere de forma concreta al término congruencia, por tanto no suele definirla, una excepción será el concepto que nos brinda MURILLO quien entiende por sentencia congruente, aquella que adecúa las peticiones de las partes deducidas oportunamente en el pleito y la parte dispositiva de la resolución judicial ${ }^{1}$.

La congruencia tradicionalmente, se une y se estudia junto a la motivación, y esto es así porque ambas se relacionan con la decisión última del proceso, la congruencia con la decisión de acceder o no a la petición y la motivación con su porqué. En este sentido el Derecho romano lo primero que nos muestra es que, si atendemos a la cronología histórica, la sentencia será primero congruente y más tarde, motivada explícitamente ${ }^{2}$. Indudablemente, el juez cuando decide, lo hace motivado por algo, pero la obligación jurídica de explicar expresamente su voluntad es posterior. Si bien, tanto la congruencia como la motivación manifestada por el juzgador, serán fundamentales para poder recurrir la decisión y armar una buena defensa. Si se carece de motivación la indefensión es clara, puesto que no se pueden romper los razonamientos del juzgador que le han llevado a condenar, y como consecuencia proponer otra solución que cambie el sentido de esa sentencia recurrida.

La necesidad de congruencia obedece a que la conclusión definitiva del proceso no puede ser arbitraria, para evitarlo el juzgador está sujeto y obligado, a responder únicamente a las pretensiones planteadas por las partes, centradas en los hechos que resulten probados, "da mihi factum, dabo tibi ius". El efecto principal será, que sobre estas pretensiones y con esos actores tampoco se puede volver a entablar nuevo juicio, es decir, la extensión del efecto res iudicata ${ }^{3}$ ya presente en los procesos romanos.

Los hechos como presupuesto de la congruencia son esenciales para el contenido de la sentencia que además cuenta con un contenido jurídico, pues bien, la congruencia se centra en el primero, es decir, en los hechos que prueban la pretensión y que condicionan el fallo. Y esto es así, porque el juez no está sujeto al derecho alegado, dado que, si se afirma un contenido jurídico inadecuado, el juzgador puede mudarlo directamente por el correcto y adaptarlo al caso concreto, en aplicación del principio iura novit curia. Como advierte TALAMANCA ${ }^{4}$, ya en el procedimiento formulario rige este principio aunque no esté abiertamente formulado. Así,

1 Murillo Villar, A., La motivación de la sentencia en el proceso civil romano. Cuadernos de Historia del Derecho $\mathrm{n}^{\circ}$ 2, 11-46. Madrid, Editorial Complutense, 1995, p.11.

2 Respecto a la motivación véase MuRILlo VillaR, A., op, cit. p. 11 y ss., también del mismo autor: Antecedentes históricos de la obligación de motivar las decisiones judiciales en el Derecho español. Teoría e storia del diritto privato, 2012, p. 8 y ss. Concretamente en la primera obra citada, p. 45, advierte que la motivación de las sentencias es algo connatural a cualquier proceso, negarla en la cognitio oficial, es minusvalorar la técnica procesal romana. Añade que, según las fuentes, hasta el siglo III no encontramos ni juristas, ni constituciones, que expongan o recojan cuestiones acerca de las sentencias motivadas y su exigibilidad. Será a partir del siglo IV, según C. Th. 4, 17, 2 y C. 7. 44. 2, cuando pasará a ser una exigencia formal. Ni siquiera una vez obligatoria la motivación se mantiene en el tiempo, así en la Novísima Recopilación de las leyes de España T.V. Libro XI, título XVI, Ley VIII, Don Carlos II, por Real Cédula de 23 de junio de 1778 obliga a que cese la práctica de motivar las sentencias y extenderlas en latín. También en ORTELls RAMOS, M., Origen histórico del deber de motivar las sentencias, Revista de Derecho Procesal Iberoamericana. $1977, \mathrm{n}^{\circ} 4$, p. 899 y ss.

3 Modestino en D. 42. 1. 1. Res iudicata dicitur, quae finem controversiam pronuntiatione iudicis accipit.

4 Talamanca, M., Instituzioni di Diritto romano. Milano, Giuffrè, 1990, p. 354. 
cuando las cuestiones eran complejas, el juez, que era lego, era socorrido por los responsa prudentium y por los rescripta del emperador que le perfeccionaban en estos aspectos. También lo confirma D. 49. 8. 1. 2 cuando señala que, si se juzga contra las sacras constituciones, es decir, contra derecho, se permite la apelación; o en C. 7. 64. 2, cuando se advierte que el juez debe decidir secundum leges, lo contrario se corrige con la emisión de una sentencia sin fuerza vinculante. Por todo lo anterior, la coherencia se refiere al contenido fáctico del proceso, sobre él que recaerá la prueba, y consecuencia de lo probado deberá resultar una decisión congruente.

Otra dificultad añadida a la posible definición de congruencia en Derecho romano resulta de la propia existencia de dos sistemas procesales con tres procedimientos, en los que no siempre podremos entender que hay sentencias congruentes, como sucederá en los más antiguos, aunque poco a poco, se vaya conformando un concepto de congruencia similar al actual.

Quizá esta circunstancia haga que hoy día, con un único proceso civil, este concepto sea mucho más claro tanto doctrinalmente, como jurídicamente. Doctrinalmente, sabemos que la sentencia debe ser congruente y estar motivada ${ }^{5}$, puesto que es un acto personal del juez, no libérrimo ${ }^{6}$, sino condicionado por la función que desempeña: decidir de forma definitiva, sobre las cuestiones que en exclusiva se han planteado en ese pleito civil por las partes procesales. Será en Derecho procesal dónde encontramos múltiples definiciones de ella. Sirvan como ejemplos los siguientes: la conformidad que debe existir entre la sentencia y la pretensión o pretensiones que constituyen el objeto del proceso ${ }^{7}$; la correlación que debe existir entre la pretensión procesal $\mathrm{y}$, otras peticiones y alegaciones de las partes y la actividad decisoria o resolutoria que se plasma en la sentencia ${ }^{8}$; a sensu contrario se habla de la falta de adecuación entre las pretensiones de las partes formuladas oportunamente y la parte dispositiva de la resolución judicial ${ }^{9}$; o conformación de la sentencia al pedimento ${ }^{10}$, entre otras. La congruencia se concibe, por tanto, como un principio procesal, incluido dentro del debido proceso, como un límite al poder discrecional del juez. La incongruencia incluso, en sus supuestos más graves, puede estar relacionada, como ya hemos advertido, con la arbitrariedad, serán aquellos casos en los que el juez excede su potestad, bien porque éste concede más o diferente de lo pedido, menos, o dicta una resolución que en sí misma es contradictoria.

5 Murillo Villar, A., La motivación..., cit., p.11, ya advierte que actualmente, en cualquier sistema procesal mínimamente desarrollado, se exige que toda sentencia, además del fallo o parte dispositiva, reúna dos requisitos fundamentales: que sea congruente y que esté motivada.

6 RodrígueZ Aguilera, C, La sentencia, Barcelona, Bosch, 1974, p. 13 y 14.

7 Guasp - Aragoneses, J., Derecho Procesal Civil, T. I. Madrid, Thomson, 2005, p. 540.

8 ORTElls Ramos, M., Derecho procesal civil, Navarra, Aranzadi, 2017, p. 348

9 Serra DomingueZ, M., "Incongruencia civil y penal" en Estudios de Derecho Procesal, Barcelona, Ariel, 1969, p. 395, 397.

${ }^{10}$ Prieto CASTRO Y FerRÁNDIZ, L., "El principio de congruencia como limitación de las facultades de la jurisdicción”, Trabajos y orientaciones de Derecho procesal, Revista de Derecho privado. Barcelona, 1969, p. 288. 
Por otro lado, jurídicamente, su regulación descansa en el artículo 218.1 de la Ley de Enjuiciamiento Civil del 2000, que es bastante descriptivo, primero se refiere al concepto ${ }^{11}$, seguido hace una referencia al iura novit curia $^{12}{ }^{13}$, en su punto segundo alude a la motivación ${ }^{14}$, finalizando con una referencia a la exhaustividad de la sentencia ${ }^{15}$.

Advertir que se aplica tanto en las sentencias civiles como penales, es obvio puesto que conforma parte de los requisitos internos de la sentencia, si bien nosotros centramos nuestro estudio en el proceso civil, dado que es en el que rige el principio dispositivo y de aportación de parte, esencialmente unidos a la congruencia ${ }^{16}$.

En este contexto se dicta la sentencia del Tribunal Supremo Sala de lo Civil 23 de diciembre de 2015 que prohíbe las cláusulas suelo, dentro de la aplicación de las normas comunitarias que se han dictado para tutelar los derechos de consumidores y usuarios en el ámbito del derecho bancario. Sentencia que guarda relación con otras ${ }^{17}$ que están revisando el contrato de préstamo hipotecario suscrito para garantizar la compra de vivienda, y fundamentalmente la Directiva 93/13/CEE del Consejo, de 5 de abril de 1993, sobre las cláusulas abusivas en los contratos celebrados con consumidores, que incluso han dado lugar a que el legislador impulsara una nueva normativa hipotecaria nacional, la Ley de los Contratos de Crédito Inmobiliario, Ley 5/19 de 15 de marzo.

11 “1. Las sentencias deben ser claras, precisas y congruentes con las demandas y con las demás pretensiones de las partes, deducidas oportunamente en el pleito. Harán las declaraciones que aquéllas exijan, condenando o absolviendo al demandado y decidiendo todos los puntos litigiosos que hayan sido objeto del debate."

12 "El tribunal, sin apartarse de la causa de pedir acudiendo a fundamentos de hecho o de Derecho distintos de los que las partes hayan querido hacer valer, resolverá conforme a las normas aplicables al caso, aunque no hayan sido acertadamente citadas o alegadas por los litigantes."

13 Actualmente el principio iura novit curia comporta que el derecho alegado por la parte no obliga al juzgador a efectos de congruencia, siempre que no modifique la causa petendi, lo contrario STA TC 166/2006 de 5 de junio, sería dictar resolución sin debate. Según esta sentencia del TC, FJ 5, concurre una incongruencia omisiva y una incongruencia extra petitum, aplicándose por parte de este Tribunal los cánones de enjuiciamiento aplicados a esos dos tipos de incongruencia. "Sobre el vicio de incongruencia con relevancia constitucional numerosas resoluciones de este Tribunal han configurado un cuerpo de doctrina, según el cual «el vicio de incongruencia, entendido como desajuste entre el fallo judicial y los términos en que las partes han formulado sus pretensiones, concediendo más o menos o cosa distinta de lo pedido, puede entrañar una vulneración del principio de contradicción constitutiva de una efectiva denegación del derecho a la tutela judicial siempre y cuando la desviación sea de tal naturaleza que suponga una sustancial modificación de los términos en los que discurrió la controversia procesal. El juicio sobre la congruencia de la resolución judicial precisa de la confrontación entre su parte dispositiva y el objeto del proceso delimitado por sus elementos subjetivos - partes-y objetivos - causa de pedir y petitum -. Ciñéndonos a estos últimos, la adecuación debe extenderse tanto al resultado que el litigante pretende obtener, como a los hechos que sustentan la pretensión y al fundamento jurídico que la nutre, sin que las resoluciones judiciales puedan modificar la causa petendi, alterando de oficio la acción ejercitada, pues se habrían dictado sin oportunidad de debate, ni de defensa, sobre las nuevas posiciones en que el órgano judicial sitúa el thema decidendi »" (STC 264/2005, 24 de octubre, F. 2, y 40/2006, de 13 de febrero, F. 2). Incluso jurisprudencia constitucional referida a la ley de Enjuiciamiento anterior como la STA TC 20 de mayo de 1991, también nos advierte de que "los tribunales no tienen necesidad ni obligación de ajustarse en los razonamientos jurídicos.... Sin que ello suponga incongruencia procesal alguna".

14 “2. Las sentencias se motivarán expresando los razonamientos fácticos y jurídicos que conducen a la apreciación y valoración de las pruebas, así como a la aplicación e interpretación del derecho. La motivación deberá incidir en los distintos elementos fácticos y jurídicos del pleito, considerados individualmente y en conjunto, ajustándose siempre a las reglas de la lógica y de la razón."

15 "3. Cuando los puntos objeto del litigio hayan sido varios, el tribunal hará con la debida separación el pronunciamiento correspondiente a cada uno de ellos."

16 El estudio se centra en el proceso civil, en el proceso penal también es aplicable el principio porque el artículo 142 de la Ley de Enjuiciamiento Criminal, no menciona la congruencia de forma expresa por lo que se aplica de forma supletoria la ley civil, pero dados los principios procesales y el propio proceso penal su contenido es diferente al civil y no es objeto de este estudio.

17 En este sentido las principales sentencias son la del Tribunal Supremo de 9 de mayo de 2013 y la del Tribunal de Justicia de Unión Europea de 21 de diciembre de 2016. 
En esta sentencia del 2015, se trata, entre otras cosas, en su fundamento jurídico segundo, precisamente de lo que a nosotros nos atañe: la congruencia y para ello, refiere el artículo 218 de la Ley de Enjuiciamiento Civil. Esta resolución se fija en los principios de justicia rogada e incongruencia por alteración de la causa petendi. Según dice el órgano juzgador, el motivo se concreta en que, en la demanda, la razón de pedir la nulidad de la cláusula suelo se centraba en un pretendido desequilibrio entre las partes y, sin embargo, la condena se ha basado en una falta de transparencia de aquélla. Este cambio se justifica por la Sala basándose en que este aspecto ha sido ya resuelto por ella en el auto de 6 de noviembre de $2013^{18}$.

En aquella resolución del 2013 se establecía que «en la medida en que sea necesario para lograr la eficacia del Derecho de la Unión, en los supuestos de cláusulas abusivas, los tribunales deben atemperar las clásicas rigideces del proceso, de tal forma que, en el análisis de un eventual abuso de las cláusulas cuya declaración de nulidad fue interesada, no es preciso que nos ajustemos formalmente a la estructura de los recursos. Tampoco es preciso que el fallo se ajuste exactamente al suplico de la demanda, siempre que las partes hayan tenido la oportunidad de ser oídas sobre los argumentos determinantes de la calificación de las cláusulas como abusivas».

El auto recordó que la "correlación o concordancia entre las peticiones de las partes y el fallo de la sentencia en que consiste la congruencia no puede ser interpretada como exigencia de un paralelismo servil del razonamiento de la sentencia con las alegaciones o argumentaciones de las partes, puesto que el deber de congruencia es compatible con un análisis crítico de los argumentos de las partes e incluso con el cambio de punto de vista jurídico expresado con el tradicional aforismo "iura novit curia" [el juez conoce el derecho] siempre que ello no suponga una mutación del objeto del proceso que provoque indefensión (por todas, sentencia núm. 365/2013, de 6 de junio)".

Según nuestro Derecho vigente y nuestra Jurisprudencia, la congruencia supone la correlación, no mimética, entre lo que han sido las pretensiones de las partes y el fallo, y puede ser congruente una sentencia que resuelva algo diferente a lo solicitado, si ambas partes han podido expresarse y alegar lo que a su derecho convenga, sin suponer una mutación del objeto del proceso que provoque indefensión ${ }^{19}$. El Tribunal Constitucional en sentencia 9/1998 de 13 de enero llega a precisar que la falta de congruencia incluso puede causar una lesión al derecho fundamental a la tutela judicial efectiva del artículo 24 de nuestro Texto Constitucional. Veamos si en Derecho romano se comparte este contenido respecto a la congruencia para así, como dice MURILLO poder aportar al jurista de derecho positivo, principios y contenidos, que le permitan criticar, y analizar con profundidad las soluciones que se han dado a lo largo del tiempo ${ }^{20}$.

18 En esa sentencia se resolvía el incidente de nulidad de actuaciones deducido contra una sentencia del Pleno $\mathrm{n}^{\circ}$ 241/2013, de 9 de mayo.

19 Según la sentencia del Tribunal Supremo de 1 de julio de 2016, una sentencia será incongruente por infracción de sus normas reguladoras por concederse lo no pedido. Otra sentencia de la Sala I de 19 de febrero de 2016 del mismo Tribunal también se refiere a la necesidad de no volver a analizar cuestiones que no han sido objeto de recurso de apelación ni en el escrito de oposición al mismo por haber quedado firmes sin impugnación.

${ }^{20}$ Murillo VILlar, A., ¿Para qué sirve el Derecho romano? Razones que justifican su docencia e investigación en el siglo XXI, Santiago de Compostela, Andavira, 2018, p. 161, 163. El Derecho romano también tiene su reflejo en estos conceptos jurídicos procesales, y puede aportar en la construcción de un nuevo derecho común europeo, y es útil, puesto que como añade MURILLO, Europa no se va a inventar ningún ordenamiento stricto sensu, sino que va a partir de aquellas regulaciones comunes y tradicionales. 


\section{RECONOCIMIENTO IMPLÍCITO DE LA CONGRUENCIA EN LAS FUENTES JURÍDICAS ROMANAS: EVOLUCIÓN EN SUS DISTINTOS SISTEMAS PROCESALES.}

Los romanistas, cuando estudian la sentencia, ya hemos señalado que no se refieren expresamente a la congruencia con este término. Su reseña es implícita y la aproximación a su concepto viene dada del análisis de expresiones como éstas: principio de fidelidad de la fórmula $^{21}$; dar sentencia conforme a los términos de la fórmula procesal ${ }^{22}$; la sentencia debe ajustarse, en cuanto a su contenido al programa procesal ${ }^{23}$; el juez está estrechamente unido a los términos de la controversia, a los concepta verba de la fórmula ${ }^{24} \ldots$, todas ellas expresiones relacionadas con la congruencia básicamente en el procedimiento formulario. Esto nos hace pensar, que indudablemente, se ha estudiado la congruencia por los romanistas, pero sin reparar en ello, así es curioso ver como estudios y textos jurídicos romanos sobre la responsabilidad del iudex, sobre la motivación de la sentencia romana, o sobre el mismo principio de litem suam facere tienen otra lectura desde la congruencia. Pasemos a analizar esta coherencia procesal con más detalle, en los distintos sistemas romanos.

\subsection{En el ordo iudiciorum privatorum}

En este sistema procesal tenemos que referir que son muchas las dificultades para encontrar fuentes fiables de las cuales colegir la cuestión que nos ocupa, esa correspondencia entre lo pedido y lo referido en la sentencia.

\subsubsection{Legis actiones}

La primera y fundamental dificultad con la que nos encontramos, es que este procedimiento era eminentemente oral ${ }^{25}$ por lo que no lo conocemos con detalle, y resulta muy arduo apreciar la existencia de congruencia en la sentencia. Sabemos que las partes debían estar presentes, que debían pronunciar sus pretensiones con gran precisión y a este respecto, ya Gayo, en Instituciones 4.11, advierte que, en las acciones de ley, el reclamar sin fidelidad a la acción, puede dar al traste con la petición. Da el conocido ejemplo del reclamo de unas cepas cortadas, alegando una acción de las XII Tablas que se refiere a árboles cortados, por la que el demandante solicita ser resarcido, pero como en su petición relata cepas y no árboles cortados pierde la cosa reclamada. El iudex no tiene ninguna facultad ni siquiera para adecuar el lenguaje de lo pretendido, que debe coincidir exactamente con la acción de petición. Esta rigidez en la primera fase del proceso nos hace pensar que el juez carecía de toda discrecionalidad a la hora de decidir. Lo

${ }^{21}$ Sirva como ejemplo PANERo GutIÉRreZ, R., Derecho romano, Valencia, Tirant lo Blanch, 2008, p. 179 dice el autor que la sentencia se debe ajustar exactamente a la fórmula, a lo que en ella figura sin poder corregir cualquier posible error y sigue explicando casos de congruencia, como en el caso de que se pida más de lo debido, plus petitio, al no resultar probada en su totalidad la pretensión del actor, deberá, necesariamente absolver, y en cita pone ejemplos referidos a cantidad, peticiones de obligaciones alternativas en las que se exigen ambas en vez de una sola,... casos en los que el actor pierde el litigio y la posibilidad de entablar otro; y en cambio indica como tratándose de minus petitio, el actor puede reclamar el resto.

22 D’ORS, A., Litem suam facere, Roma, Pontificia Universitas Lateranensis. 1982, p. 370.

${ }^{23}$ KASER, M., Derecho romano privado, Madrid, ed. Reus, trad. esp., $2^{\circ}$ ed, 1982, p. 378.

${ }^{24}$ TALAmANCA, M., op, cit, p. 333.

${ }^{25}$ Por todos, TalamancA, M., op, cit., p. 296-298, ya indica el conocimiento escaso del proceso de las legis actiones tanto en sus fases in iure como apud iudicem. Tampoco se conoce mucho sobre la sentencia en este procedimiento. 
sentenciado son decisiones puramente declarativas y orales, por ejemplo en la legis actio per sacramentum in rem, la verdadera cuestión litigiosa quedaba como algo secundario e implícito, tras la complicada ceremonia del sacramentum ${ }^{26}$. De ahí que, en términos de congruencia, no podamos concluir su exigencia.

Mientras hoy se discute si la congruencia puede entenderse como requisito interno de la sentencia o como principio del proceso, ya se considere autónomo o se estime derivación del principio dispositivo ${ }^{27}$, desde el Derecho romano podemos indicar que, si nos atenemos a su origen, la congruencia no es un requisito autónomo de la sentencia, al menos en las legis actiones. Más adelante, con la inclusión de un principio dispositivo más consolidado, así como la aplicación del principio contradictorio y de aportación de parte, sí se exigirá congruencia, si bien nunca expresamente.

\subsubsection{Procedimiento formulario}

De la bipartición del proceso en el procedimiento formulario se infiere la existencia o inexistencia de congruencia en las sentencias, puesto que tenemos dos puntos neurálgicos, íntimamente relacionados, que nos sirven a este propósito: la litis contestatio al final de la fase in iure y la sentencia de la fase apud iudem. Así, el juez en la fórmula, en ese breve escrito, bien en la condemnatio, bien en la adiudicatio, deja predeterminada la cuestión del litigio y determina el contenido de la futura sentencia que el iudex privatus dictará. Desde ese momento, queda inalterable quiénes son los litigantes, su legitimación o interés en el pleito, la cosa o la cuantía litigiosa reclamada, el fundamento jurídico o causa petendi y por supuesto, el iudex elegido. Es decir, se observan los requisitos de congruencia subjetivos y objetivos: correlación en cuanto a las partes procesales, pues la sentencia no se va a poder imponer a sujetos fuera de la relación procesal sub iudice; y respecto al objeto del proceso, se decidirá sobre la prestación aducida, la relación jurídica, o el acto o negocio jurídico tratado, y no otro.

Esta fijación de los términos conduce a diferentes consecuencias ${ }^{28}$, primero, que el juez sólo puede afectar en su sentencia a estos litigantes o sus representantes ${ }^{29}$; que lo será respecto a la cosa litigiosa o la cuantía pecuniaria solicitada, así, si ésta era cierta el juez se debe atener a esa petición, aun a riesgo de que haya cambio de valor posterior a la litis contestatio y antes de la sentencia; que en la litis se añada la contestación del demandado, y que con todos estos elementos quede fijado el litigio, es decir, la causa petendi, puesto que posteriormente, por la regla de ne bis in ídem, no cabe otro pleito con los mismos sujetos, objeto y causa de pedir, estamos ante una res iudicata. Como bien dice TALAMANCA, el contenido de la sentencia venía predeterminado de forma más o menos precisa en la condemnatio, es más, añade que sólo esa parte de la fórmula será sobre la que la voluntad de las partes y el iussum iudicandi del magistrado otorguen

\footnotetext{
${ }^{26}$ Murga Gener, J. L., Derecho Romano Clásico, II. El Proceso, $2^{\circ}$ ed. Zaragoza, Prensas Universitarias de Zaragoza, 1983, p. 141.

${ }^{27}$ DE La Oliva Santos, A., Sobre la congruencia de la sentencia civil. Sobre la congruencia de la sentencia civil y penal. Derecho y proceso. Estudios jurídicos en honor del Prof. A. Martínez Bernal, Murcia, Universidad de Murcia, 1980 , p. 591.

${ }^{28}$ Murga Gener, J. L, op. cit., p. 299 y ss.

${ }^{29}$ El Procurator, que había sido incluído en la fórmula será quien después aparecerá en sentencia y el llamado a ejecutarla por la actio iudicati.
} 
poder al iudex para condenar o absolver, "qua iudici condemnandi absolvendive poetesta permittitur" ${ }^{30}$. En este procedimiento "la ley para el juez era la fórmula" ${ }^{31}$.

En D. 10. 3. 18, explica Javoleno que la potestad del juez no puede extenderse más allá de lo que se dedujo en el juicio. Y es un deber tal, que la falta de congruencia se penaliza, así por ejemplo cuando la condemnatio de la fórmula es certa y el juez decide más o menos de esa cantidad, litem suam facere, (Gayo 4, 50 y 52). Igual sucede cuando el pretor hubiere señalado una taxatio $^{32}$ y el juez desobedece la cláusula dumtaxat sestertium decem milia condemnato (Gayo 4, 51 y 52). Por tanto, no sentenciar conforme al tenor de la fórmula supone que el juez quede obligado a hacer suyo el proceso, y la consecuencia es cometer ese cuasidelito, que en opinión mayoritaria de la doctrina presume que el pronunciamiento es nulo ${ }^{33}$, aunque Gayo en su obra no lo indique explícitamente.

La congruencia en el procedimiento formulario sí se va conformando, concretamente afecta al contenido de la sentencia; la condemnatio era parte esencial de la fórmula (salvo en las acciones prejudiciales o declarativas) por la que se otorga al juez la facultad de absolver o condenar, según resulten probadas las pretensiones incluidas en ella. La vinculación del juez es clara, la condemnatio le obliga a decidir con poco margen de discrecionalidad, pero con más amplitud que en las legis actiones, al menos con el suficiente como para valorar si se está o no respondiendo en la sentencia de modo acorde a lo pedido.

Revisando los casos de condemnatio certa, cuando la suma a que el juez deberá condenar está determinada en la intentio (G. 4, 40.50,52) la sentencia sólo puede ser congruente, no cabe la incongruencia porque la cantidad está prefijada en la cantidad estimada que se concede o deniega. Algo similar sucede con la condemnatio incerta, pero en este caso el juez tiene cierto margen para determinar esa suma, y decidir si concede el máximo o el mínimo de la cantidad referida. Éstas a su vez pueden ser condemnatio incerta cum taxatione en la que se le fija al juez un límite o una cantidad máxima a tener en cuenta en la sentencia (G. 4. 51) o condemnatio incerta en la que no se limita al juez la cantidad a que debe condenar que será el valor del objeto litigioso, quanti ea res erit, tantam pecuniam ... o quanti interest, en la que se obliga al juez a condenar por una suma equivalente a los daños y perjuicios sufridos, (G. 4. 51); otra condemnatio incerta es quidquid dare facere oportet ex fide bona, en la que se obliga al juez a que condene con arreglo a lo que se debe dar o hacer según la buena fe. En estos casos la labor del juez no es tan automática y existen posibles resoluciones, todas diferentes, pero congruentes. Como se resume en I. 4. 6. 32, el juez debe cuidar de proferir siempre, en cuanto le sea posible, sentencia de cantidad determinada o de cosa cierta, aunque ante él se haya procedido por cantidad incierta $^{34}$.

30 TAlamancA, M., op, cit., p. 354 y p. 310. Según KASER M., op. cit., p. 378, la sentencia debe ajustarse en cuanto a su contenido al programa procesal.

${ }^{31}$ PARICIO, J., Sobre la administración de la justicia en Roma: los juramentos de los jueces privados, Madrid, Civitas, 1987, p. 75.

${ }^{32}$ La taxatio suponía que el importe de la condena no podía exceder de un maximum, el juez, por tanto, quedaba obligado en su aestimatio a no sobrepasar ese quantum, aunque sí que podía condenar a una cantidad menor, limitando el poder de decisión del juez. La taxatio en las actiones bonae fidei está documentada, principalmente en la compraventa (D. 19.1 de actionibus empti et venditi; C. 4. 49), disponiendo que la suma a fijar en la condemnatio la debía medir el juez, con lo que se permitía incluir la cláusula de la taxatio para fijar el límite máximo de condena en la sentencia.

${ }^{33}$ D’ORs, A., op.cit., p. 372. CREMADES, I., Y PARICIO, J., La responsabilidad del juez en el Derecho romano clásico, en AHDE 54, 1984, p. 183, GIUSTO. Per una storia del litem suam facere. Studia et documenta historiae et iuris, $\mathrm{n}^{\circ} 71$. 2005, Città del Vaticano, p. 462. FuENTESECA, M., El enigmático significado de litem suam facere. IVRA: rivista internazionale di diritto romano e antico, $\mathrm{n}^{\circ} 63-2015$, Napoli, p. 30.

${ }^{34}$ D. 7. 4. 6. 32. Curare autem debet iudex, ut omnimodo, quantum possibile ei sit, certae pecuniae vel rei sententiam ferat, etiamsi de incerta quantitate apud eum actum est. 
En este contexto del procedimiento formulario, Ulpiano, en D. 42. 1. 55, advierte que, si un iudex condenó a más o menos, no puede alterar su sentencia. Esto puede interpretarse como que el juzgador puede dar sentencias válidas con contenidos diferentes a la fórmula ultra petita o infra petita y, sin embargo, ser inamovibles. De ahí que, ese efecto de cosa juzgada que adquiere la sentencia, deba ser contrarrestado de alguna forma, en este caso la prevista es el cuasidelito, que penaliza al juzgador, a quien hace subrogarse en la posición del afectado y hacer suyo el proceso. Todo ello con más razón si, como sucede en el ordo iudiciorum privatorum, no hay apelación posible, ni órgano ante el que revisar esta sentencia. Por tanto, la resolución incongruente que no es evitable en sí misma, en todo caso puede ser causa de sanción para el juez, pero a posteriori.

\subsubsection{Responsabilidad por incongruencia: litem suam facere}

La reprobable conducta del juez que litem suam facere abarca supuestos más allá de la mera responsabilidad del juez que dicta sentencia sin ajustarse a la fórmula ${ }^{35}$, de tal modo que su contenido se extiende a supuestos sobre la responsabilidad del juez por falta de imparcialidad al dictar sentencia, incluyendo en su descripción posibles casos de dolo, (D. 5.1.15.1), que quedarían fuera de los supuestos de incongruencia.

Pero lo que nos interesa son otros supuestos castigados por este cuasidelito, los casos de incongruencia omisiva o ex silentium, es decir, la falta de respuesta al litigio, no obedecer lo prescrito por el officium iudicis, D. 5. 1. 74. pr. (Jul. 5 dig.), D. 42.1 .55 (Ulp. $51 \mathrm{ad} \mathrm{Sab.),} \mathrm{casos}$ de simple omisión, sin ser una negativa a juzgar. Esta circunstancia, que se refiere a la exhaustividad de la sentencia, invita a reflexionar sobre si cabe la respuesta parcial a las pretensiones de un pleito (actualmente no es posible) y si esto podía dar lugar a una sentencia incongruente o solamente incompleta, y en ese caso lo que procede es completarla a petición de parte, y con ello evitar el cuasidelito.

Para sortear la sanción por esa conducta omisiva, el único remedio con el que cuenta el juzgador es iurare sibi non liquere. Cuando el iudex era nombrado, prestaba un juramento por el que se obligaba a actuar con arreglo a lo bonum et aequum ${ }^{36}$, de ahí que si quería exonerarse de ese compromiso, y por tanto apartarse del juicio y no resolver, debía volver a jurar, esta vez con el juramento de no ver clara la solución del pleito. De tal manera que, al liberarse del primer juramento, se podía proceder a nombrar otro iudex. Tenemos pocas noticias sobre esta práctica, sabemos que antes de dar este paso el juez tenía la opción de retrasar su veredicto utilizando un aplazamiento por medio de la diffissio ${ }^{37}$, pero si después seguía sin argumentos para resolver, podía iurare sibi non liquere ${ }^{38}$.

${ }^{35}$ Cremades, I., Y PARICIO, J., op. cit,, p. 179 y ss., D’Ors, A., op.cit., p. 368 y ss. DE MARTINO, F., Litem suam facere, Bulletino dell'Istituto di Diritto Romano "Vittorio Scialoja", 1988, p. 1 y ss. FuENTESECA, M., op.cit. p. 29 y ss. GiUSTO, op. cit., p. 457 y ss. SCAEVOLA In margine al litem suam facere in età postclassica e giustinianea. SDHI. Studia et documenta historiae et iuris, $\mathrm{n}^{\circ} 79,2013$, p. 423 y ss.

${ }^{36}$ Justiniano en una Constitución referida en C. 3. 1. 14. pr. menciona la antigua obligación de jurar de los jueces, de cómo iban a acordar sentencia definitiva conforme a la verdad y a la observancia de las leyes.

${ }^{37}$ Ulpiano, D. 4. 8. 13. 4. (Ulp. 13 ad ed.) indica que, si el juez es apremiado por el Pretor para dictar sentencia, será muy justo que, si jura no estar aún bien instruido, se le dé espacio para pronunciar su juicio.

${ }^{38}$ PARICIO, J., "Iurare sibi non liquere", en Atti del III Seminario romanistico gardesano (Milán, 1988), p. 414-416. Del mismo autor Sobre la administración de la justicia en Roma: los juramentos de los jueces privados, Madrid, Civitas, 1987 , p. 21 y ss. 
Como hemos visto, el iudex tiene obligación de resolver (D. 5. 1. 74), (D. 42. 1. 55) sino incurre en responsabilidad, además lo debe hacer de manera congruente, vinculado con la fórmula. Es más, el iudex responderá de todos los casos en los que su sentencia produzca perjuicio a los litigantes, puesto que no hay apelación posible. La consecuencia para el iudex no era baladí, dado que en estos casos podía ser perseguido por medio de la actio si iudex litem suam facere . $^{39}$. Este cuasidelito al que ya se alude en las XII Tablas, suponía la sanción al juez que emitía una sentencia injusta, lo que podía arrastrar otro efecto, cual es que la víctima interpusiera contra el juez una actio in factum dirigida a hacerle pagar una pena pecuniaria calculada in id quod aequum iudici videbitur. Ante este riesgo, el juez gozaba del iurare sibi non liquere ${ }^{40}$. Un caso especial supone la actuación de un órgano judicial colegiado, así en un texto de Paulo, D. 42. 1. 36 (Paul. 17 ad ed.) se alude a un caso en el que siendo varios los juzgadores, sólo uno no vea claro, y advierte que en tal caso la sentencia prevalece, aunque aquél disienta.

Como podemos observar, en el procedimiento formulario, no hay una consecuencia mimética entre lo pedido en la demanda junto a la contestación, con el respectivo fallo; no es preciso que éste se ajuste exactamente al suplico de la demanda, siempre que las partes hayan tenido la oportunidad de ser oídas. A este respecto el juez no incurrirá en responsabilidad y estará obligado a pronunciar sentencia si, como dice Juliano, en D. 5. 1. 74. 1, el juez a quien se demandó juzgar hasta cierta suma, juzga sobre mayor cuantía, cuando se haya convenido entre los litigantes, o dicho de otro modo, si hay acuerdo entre $\operatorname{ambos}^{41}$. Con esto nos vamos aproximando al concepto de congruencia actual, puesto que, con ese acuerdo de las partes, además se cumplen principios procesales como el de contradicción o el de aportación de parte.

Así pues, en el ordo iudiciorum privatorum nace la exigencia de la congruencia en el procedimiento formulario, aunque no en toda la extensión del concepto. La estructura bipartita de estos procesos la favorece, ya que a la vez que se elige al juez llamado a sentenciar, se fijan los términos sobre los que debe pronunciarse. LLOBELL advierte que este principio de fidelidad a la fórmula es tan absoluto que sí, siguiéndola se concluye en una sentencia absurda, el juez no tiene facultades para evitarla ${ }^{42}$, salvo por la ya citada inhibición del juramento rem sibi non liquere. SAVIGNY nos indica que en el procedimiento formulario la intentio y la demonstratio servían para fijar el contenido y la extensión de lo que debía adquirir la autoridad de cosa juzgada en virtud de la sentencia ${ }^{43}$, y CALAMANDREI añade que la fórmula es una sentencia hipotética, que el juez debe transformar en definitiva apurando los hechos ${ }^{44}$.

Como resumen, en este procedimiento la congruencia ya es un requisito interno, natural y esencial del fallo. La congruencia, como elemento de la sentencia, aunque guarda mucha relación con la motivación, es decir, con el por qué el juez llega su conclusión, es anterior a la expresión de esta última, dado que en este sistema la razón o razones por la que el iudex funda su decisión no se tienen que explicitar ${ }^{45}$. Las partes procesales y el magistrado determinan en la fase

39 Vid. CREMADES, I., Y PARICIO, J., op, cit., p. 179 y ss.

${ }^{40}$ PARICIO, J., "Iurare .... p. 411 y ss., MurGa Gener, J. L, op, cit, p. 66 y 314.

${ }^{41}$ De qua re cognovenit iudex, pronuntiare quoque cogendus erit. 1. Iudex, qui usque ad certam sumnam iudicare iussus est, etiam de re maiori iudicare potest, si inter litigatores conveniat.

${ }^{42}$ LlOBell TuseT, J., Historia de la motivación de la sentencia canónica. Zaragoza, Edita Caja de ahorros y Mote de Piedad de Zaragoza, Aragón y Rioja, 1985, p. 23 Para ello cita a SÉNECA en De Beneficiis, III, 8, 5 "Illum (iudicem) formula includit et certos, quos non excedat, términos ponit” y a CICERÓN (In Verrem, II, 12,31)).

43 Savigny, M. F. C., Sistema del Derecho romano actual., trad. esp. $2^{\circ}$ ed., Tomo V-VI, reimp. Facs. 2004, Madrid, Góngora, p. 237.

${ }^{44}$ Calamandrei, P., La casación civil, T. I, Historia y Legislaciones, Vol. I trad. esp. Buenos Aires, Librería el Foro, 1961, p. 80 n $^{\circ} 83$, p. 56

${ }^{45}$ En cuanto a la motivación en el procedimiento per formulas, son varios los autores que así lo atestiguan: MURILLO, La motivación ..., cit, p. 14. CosTA, E., Profilo storico del processo civile romano, Roma, Athenaeum, 1948, p. 77. SCIAloja, V., Procedura civile romana. Esercizio e difesa dei diritti, IVS. Collezione di scritti giuridici, XV Milano- 
in iure, libremente, los términos de la sentencia, puesto que son los dueños del proceso, los que deciden cual es la cuestión debatida y que hechos deben ser probados. Y el iudex deberá decidir como consecuencia de los hechos probados, siendo responsable directo de su decisión. La congruencia, por tanto, es una consecuencia de la propia estructura bipartita de este sistema procesal, pero no alcanza la flexibilidad ni la adaptación que se consigue en la última etapa del proceso civil romano, porque la sentencia en aquél sigue siendo limitada y la responsabilidad directa del juez, no como veremos a continuación en el siguiente proceso romano la cognitio extra ordinem.

\subsection{En la cognitio extra ordinem}

La manera casi mecánica de resolver los asuntos de la etapa anterior desaparece en la nueva cognitio extra ordinem. De todos los sistemas procesales romanos es el que más se asemeja al proceso civil actual y del que tenemos más noticias pues, como dice BIONDI, el proceso moderno es de origen y estructura romana ${ }^{46}$. Surge en los primeros tiempos del Imperio, y quedará como único procedimiento, cuando los emperadores Constancio y Constante, en la Constitución de 10 de febrero de 342, suprimen definitivamente el procedimiento formulario (C. 2. 48. 1). Con él desaparece la bipartición en el proceso y por tanto será el mismo juez el que conozca el proceso de principio a fin. La justicia empieza a ser estatal y el juez se jerarquiza, incluyéndose en la estructura del Imperio, incorporando el recurso de apelación, lo que conducirá a que la responsabilidad del juez sea menos personal y más institucional.

La sentencia concede al magistrado más facultades de decisión, pero dentro del officium iudicis ${ }^{47}$ que consiste en conocer y decidir el litigio dentro del marco procesal de cada momento histórico, la sujeción a la estructura lógica de la fórmula que antes era absoluta, ahora desaparece y permite un fallo más vinculado a la peticiones de los sujetos procesales.

Si bien en la anterior litis contestatio se fijaba el contenido del pleito, en este procedimiento se transforma y se degrada, se desnaturaliza ${ }^{48} \ldots$ de ser la base axial en donde se apoyó y basculó todo el litigio clásico, pasa a convertirse en un puro momento de la tramitación procesal que, aunque mantenga la misma denominación, nada tiene que ver ya con lo que antes significó, ni conserva apenas rastro de aquél convenio arbitral que durante tantos siglos proporcionó al procedimiento antiguo y clásico su fuerza esencialmente privatística ${ }^{49}$. En la cognitio las partes procesales pierden la libertad y el protagonismo en el proceso, frente a una aplicación de la justicia reglada con estructura funcionarial. Es principal el cambio del iudex privatus al funcionario jerárquicamente ordenado en la estructura de Roma. La fijación procesal de la quaestio litigiosa es el único efecto a señalar en la litis contestatio ${ }^{50}$ de la cognitio extra ordinem que resulta relevante a efectos de congruencia, unido a la determinación del elemento subjetivo.

Desde luego, a efectos de correlación varía considerablemente, porque si bien antes, la congruencia descansaba en la libertad de que gozaban las partes y el magistrado para fijar las

Roma, 1936, p. 180. GuARINO, A., Diritto privato romano, $8^{\circ}$ ed. Napoli, Jovene, 1988, p. 231. PUGLIESE, G., Istituzioni di Diritto romano, Padova, Sintesi, 1986, p. 362.

${ }^{46}$ BIONDI, B., Intorno alla rominità del processo civile moderno, BIDR 42, Roma, 1934, p. 430: "Il proceso moderno è dunque di origine ed impostazione romana, sempreché intendiamo riferirci non a quel proceso formulare, típicamente latino, che è tramontato per sempre, ma a quella cognitio extra ordinem che sorge fin dai primi tempi dell'Impero, si consolida ed allarga via via nella prassi giudiziaria, finchè con Giustiniano si afferma come único sistema processuale."

47 Talamanca, M., s.v. Processo civile (diritto romano) en Enc. dir XXXVI, Milano, Giuffré, 1987, 1 y ss.

${ }^{48}$ KASER M., op. cit., p. 385.

49 Murga Gener, J. L., op. cit, p. 374.

${ }^{50}$ Kaser M., op. cit., p. 385. MurGa Gener, J. L, op. cit., p. 381. 
pretensiones en la litis contestatio y la solución consecuente del juzgador ${ }^{51}$, sin embargo, ahora el magistrado, que lo es de principio a fin, tiene mucha más intervención en este proceso de fase única. Asume, por un lado, la iurisdictio y por otro la iudicatio, sustituyendo al de la justicia privada, reúne más facultades respecto a su resolución, porque la función de juzgar ya no es privada, es pública y el juez ya no responde ante una decisión incongruente haciendo suyo el proceso, sino que existe la posibilidad de apelar.

El juez, por tanto, tiene gran poder discrecional, ceden las fórmulas, y las partes procesales pierden libertad, puesto que ya no eligen juzgador, las pruebas son tasadas, la litis contestatio se reduce a un mero trámite, la fijación de los términos del proceso es más difusa, por lo que a efectos de congruencia no se predetermina el contenido de la sentencia con tanta concisión, y en el contenido de la sentencia encontramos un antecedente más claro del proceso actual. Así, esta coherencia consistirá en que haya armonía entre lo solicitado por las partes (incluyendo reconvenciones, réplicas y dúplicas) y lo concedido o denegado por el juez. Ahora el juez ya puede condenar a pagar cantidad o a restituir cosa cierta, pero esto no supone que el juez nombrado para cierto asunto, pueda fallar sobre algo distinto de lo que a ese asunto se refiere, porque como se recuerda en las fuentes, en tal caso no hizo cosa válida ${ }^{52}$, como se desprende de C.7. 48. 1 (Imp. Alexander A. Sabiniano) ludex ad certam rem datus, si de aliis pronunciavit, quam quod ad eam rem pertinet, nihil egit. (223). Mostrando un primer ejemplo de incongruencia extrapetitum.

A partir de esta época, es frecuente encontrar más ejemplos de incongruencia de todo tipo. Por extrapetitum, contamos con casos en los que el magistrado resuelve cosa ajena a la promovida ante él y ello es razón suficiente para recurrir. Así, en C. 7. 48 .3, cuando los emperadores Diocleciano y Maximiano, indican que, si el juez fue nombrado para conocer de la propiedad, si no resuelve sobre ésta y en cambio responde sobre posesión, se puede recurrir ante el gobernador de la provincia.

\section{7.48 .3 (Impp. Diocletianus et Maximianus AA.et CC. Philetae) Si de proprietate datus} iudex adversus te nihil super hac statuit, rector aditus provinciae causam hanc cognoscere suaque decidere sententia curabit, cum et, si quid de possessione pronuntiatum probetur, hoc causae proprietatis minime noceat.

Otra consecuencia de este hecho es que la falta de coincidencia entre lo pedido y lo concedido no expone al juez al cuasidelito litem suam facere, la nueva solución a este problema es la appellatio.

Otro ejemplo de incongruencia lo encontramos en D. 10.3.18 a propósito de los juicios de división de cosa común, a los que se dedica el título tercero del décimo libro del Digesto ${ }^{53}$, en este precepto se nos advierte de que la potestad del juez no puede extenderse más allá de lo que se dedujo en el juicio, y el árbitro no puede disponer que un fundo de la herencia, preste servidumbre a otro fundo que no es de la herencia. Entendemos que si se ventiló un asunto sobre

${ }^{51}$ Quien en su sentencia resuelve, siendo desconocedor e imparcial respecto a la anterior fase procesal, obligado a decidir, casi maquinalmente lo que se le pregunte.

${ }^{52}$ No es claro el procedimiento referido en este texto, y dada la fecha puede ser el procedimiento formulario tardío o ya la Cognitio extra ordinem. RoBles REYES, J. R., La competencia jurisdiccional y judicial en Roma. Murcia. Ed. Universidad de Murcia, 2003, p. 24. Y en cita 50 interpreta este comentario imperial con referencia a posibles cuestiones penales concomitantes, pero el que el iudex se pueda o no pronunciar sobre estos asuntos, a efectos de congruencia, dependerá de que hayan sido o no objeto de la controversia. Si lo han sido y las partes procesales se han podido defender sobre lo refutado por la parte contraria, la congruencia queda salvada. Sin embargo, si se resuelve sobre estos asuntos sin haber sido alegados antes del pronunciamiento final, éste resultará incongruente, independiente del proceso seguido.

${ }^{53}$ D. 10. 3. 18 (Iav. II.epist.9). Ut fundus hereditarius fundo non hereditario serviat, arbiter disponere non potest, quia ultra id quod in iudicium deductum est excedere potestas iudicis non potest. 
división de herencia no es congruente, que se pueda extender a otro asunto de servidumbres, más cuando éstas se corresponden con fundos que no son del caudal hereditario.

Lo que resulta reseñable es como el juez cada vez tiene más flexibilidad a la hora de emitir su juicio, que ya no resulta tan automático; otra muestra de ello la encontramos en D. 42. 1. 59, donde Ulpiano nos indica que en las sentencias bastará que el juez haya expresado la suma, y mandado que se pague o que se entregue algo, aunque esto lo haya significado con otra cualquier palabra.

D. 42 .1. 59 (Ulp. IV. De omn. Trib.). In summa sufficiet, si expresserit iudex summam in sententia solvique iusserit vel praestari vel quo alio verbo hoc significaverit.

Otros ejemplos de acomodación y de finura de juicio los encontramos en C. 7. 46. $3^{54}$, cuando el emperador Gordiano advierte que la condena hecha sin expresión de cantidad cierta es considerada solamente, si en alguna parte de las actuaciones estuviera expresada la cantidad cierta; O bien, en D. 42. 15. 1 si el juez condena que se le restituya a Ticio lo que tiene por virtud de testamento o de codicilos de Medio, se ha de entender esto como si se hubiera expresado cantidad.

Incluso, tenemos fuentes que denotan signos de congruencia y de pulcritud jurídica en casos en los que, aunque no estén determinadas las peticiones demandadas éstas puedan ser determinables, como muestra D. 42. 1. 59. 1 cuando se resolvió que, aunque no se haya expresado la suma en sentencia, si el que pidió lo hizo y el juez dijo "paga lo que se pidió" o "cuanto se pidió" la sentencia es válida.

D. 42. 1. 59. 1 Amplius est rescriptum, etsi in sententia non sit summa adiecta, si tamen is qui petit, summam expresserit et iudex ait: «solve, quod petitum est», vel: «quantum petitum est", valere sententiam.

Esta discrecionalidad del juez, si bien es más amplia que en el ordo iudiciorum privatorum también tiene sus límites, por ejemplo, en D. 42.1.59. 2, si los que condenan a capital, fallan sin concretar "páguense los intereses, si algunos competen", o "los que competen" sin indicar el interés concreto, se nos dice que no fallan rectamente, porque deben hacer condenación cierta. En este caso el fallo no es determinable y resultaría por tanto incorrecto, al faltar el dato del tipo de interés.

D. 42. 1. 59. 2 Qui sortis quidem condemnationem faciunt, de usuris autem ita pronuntiant 'usurae si quae competunt' vel 'quae competunt, ut praestentur', non recte pronuntiant: debent enim de usuris quoque congnoscere et certam facere condemnationem.

En cambio, en C. 7. 46. 1, describe que, si el juez condenó a intereses hasta que se hubiese satisfecho la cantidad de la condena, es evidente que la sentencia no se dio contra el derecho, porque no va más allá de esa cantidad concreta, por tanto, no excede de lo pedido.

C. 7. 46. 1 Impp. Severus et Antoninus AA. Aelianae. Cum iudicem, quoad pecunia condemnationis soluta fuisset, pendendis usuris legem dixisse profitearis, non contra iuris formam sententiam datam palam est.

Un caso de infrapetitum lo encontramos en C. 3. 10. 1. 3, constitución atribuida a Zenón, cuando señala que en una demanda que se hubiese tasado en menor cantidad de la que en realidad le corresponde, el juez no lo contemple, sino que profiera sentencia por la verdadera cantidad.

${ }^{54}$ C. 7.46 .3 (Imp. Gordianus A. Aemilio). Haec sententia: 'omnem debiti quantitatem cum usuris competentibus solve' iudicati actionem parere non potest, cum apud iudices ita demum sine certa quantitate facta condemnatio auctoritate rei iudicatae censeatur, si parte aliqua actorum certa sit quantitas comprehensa. 
C. 3. 10. 1. 3 Quod si quis litem suam minoris quam re vera est taxaverit, iudex ad id non respiciat, sed in veram quantitatem sententiam ferat.

Consideración especial merece la reconvención a efectos de congruencia, el caso del demando que a su vez acciona contra el actor. Ya en C. 7. 45.14 se permite que el juez dicte sentencia no sólo de absolución del demandado sino contra el actor, y declarar que debe dar o hacer alguna cosa, sin que quepa excepción alguna. Lo congruente será resolver todo, lo pedido por el actor junto con lo reconvenido por el demandado ya que no se concederá excepción para impedirlo.

C. 7. 45. 14 (Imp. Iustinianus A. Demostheni pp.) Cum Papinianus summi ingenii vir in quaestionibus suis rite disposuit non solum iudicem de absolutione rei iudicare, sed et ipsum actorem, si e contrario obnoxius fuerit inventus, condemnare, huiusmodi sententiam non solum roborandam, sed etiam augendam esse sancimus, ut liceat iudici vel contra actore ferre sententiam et aliquid eum datoriun vel facturum pronuntiare, nulla ei opponenda exceptione, quod non competens iudex agentis esse cognoscitur. Cuius enim in agendo observavit arbitrium, eum habere et contra se iudicem in eodem negotio non dedignetur.

\subsubsection{Relación de la congruencia con la motivación}

La congruencia y la motivación son dos requisitos fundamentales de la sentencia, razón por la que están muy relacionados. Hay dos disposiciones de finales del siglo IV, recogidas en dos Constituciones Imperiales, en las que encontramos una reseña quizá más expresa a la motivación pero que también se refieren a la congruencia.

En la Constitución C. 7. 44. 2 (a. 371) de Impp. Valentinianus, Valens et Gratianus AAA..., ad Probum Praefectum Praetorio, cuando se describe cómo debe ser la sentencia, e indica que no debe ser súbita y "debe guardar fidelidad con la demanda", esta expresión llama la atención puesto que sin aludir al término congruencia la define de forma muy descriptiva, en otras palabras, la sentencia debe guardar fidelidad con lo discutido, que no será otra cosa que el negocio concreto sometido a consideración.

C 7. 44. 2 Impp. Valentinianus, Valens et Gratianus AAA..., ad Probum pp. Hac lege perpetua credimus ordinandum, ut iudices, quos cognoscendi et pronuntiandi necessitas teneret, non subitas, sed deliberatione habita post negotium sententias ponderatas sibi ante formarent et emendatas statim in libellum secuta fidelitate conferrent sctiptasque ex libello partibus legerent, sed ne sit eis posthac copia corrigendi vel mutandi. Exceptis tam viris eminentisimus praefectis praetorio quam aliis ilustrem administrationem gerentibus ceterisque illustribus iudicibus, quibus licentia conceditur etiam per officium suum et eos, qui ministerium suum eis accomodant, sententias definitivas recitare. (a. 371)

Ciertamente, de la lectura del texto se puede inferir, como señala MURILLO, que los jueces tienen la expresa y necesaria obligación de deliberar acerca del negocio sometido a su consideración $^{55}$, de ese concreto negocio. El juez debe ser cuidadoso porque se le exige reflexión, que no redacte súbitamente las sentencias, ponderándolas, teniendo en cuenta que lo debe hacer junto a la demanda, hasta en el mismo escrito.

En el Código Teodosiano encontramos otro aspecto de la congruencia, el referido al deber de exhaustividad, es decir, a la obligación de responder todas y cada una de las cuestiones litigiosas planteadas, es decir, a todo lo que los negocios encierran. No contestar pudiere dar lugar

55 Murillo Villar, A., La motivación ... cit. p. 20 
a una posible incongruencia parcial ${ }^{56}$, además responder a todo evita un nuevo pleito sobre lo mismo:

C. Th. 4. 17. 2 Impp. Valentinianus, Valens et Gratianus AA.., ad Probum Praefectum Praetorio,: Iudex in proferenda sententia quae iurgantibus prosit, ad plenum recenseat, quidquid negotii fuerit inlatum, quod senserit scribat et relegat, ne per errorem iudicis iterum a primordio novae litis sortiantur eventus. (a.382)

Sin embargo, en C. 7. 45. 15 se dice que, si en un litigio hubiese muchas cuestiones, pueda el juez sentenciar sobre algunas de ellas, y entonces conocer nuevamente de las demás, y pronunciar no una única sentencia resolviendo todas las cuestiones.

C. 7. 45.15 (Impp. Iustinianus A. Iuliano pp.) Constitutio iubet, si Litis multa capita sint, iudicem de quibusdam sententiam definitivam proferre posse ac deinde rursus sententiam quae ei placuerit, proferre, nec cogi unam sententiam pronuntiare.

Estos textos, aunque pueden parecer contradictorios, en realidad no lo son porque en la segunda cita, lo único que describe es que puede haber diferentes pronunciamientos que atiendan a la totalidad de las peticiones, no sólo una, pero esto no implica que queden sin repuesta.

En este sentido C. 7. 45. 15 advierte que, si en un litigio hubiera muchas cuestiones, pueda el juez pronunciar sentencia definitiva sobre algunas de ellas, y entonces conocer nuevamente de las demás, y proferir la sentencia que bien le hubiere parecido, y que no sea compelido a dictar una sola sentencia a la vez sobre todas las cuestiones. Ciertamente esta circunstancia hoy no es posible, se deben contestar a todos y a todo en la misma resolución, por aplicación del principio de exhaustividad que como vemos no tiene origen romano.

Esta interpretación se refuerza por D. 10. 2. 27 cuando Paulo advierte que las condenas y las absoluciones deben afectar a todos los sujetos del proceso, de forma que no será válida la sentencia que haya omitido la condena respecto a alguno se los sujetos procesales, porque como bien indica la cosa juzgada de un solo juicio no puede valer en parte, y no ser válida en otra parte.

D. 10.2. 27 (Paulus, 23 ad ed.). In hoc iudicio condemnationes et absolutiones in ómnium persona faciendae sunt: et ideo si un alicuius persona omissa sit damnatio, in ceterorum quoque persona quod fecit iudex non valebit, quia non potest ex uno iudicio res iudicata in partem valere, in partem non valere.

Tanto C 7. 44.2 (a. 371) como C. Th. 4. 17. 2 (a. 382) se recuentan los requisitos lógicos y formales de la sentencia, tendentes a evitar arbitrariedades en la decisión, que es el fin último que justifica la congruencia: ad plenum recenseat, scribat et relegat, non subitas, deliberatio et ponderatio, emendatio, conforman el quod senserit la decisión. Como advierte MURILLO, estas Constituciones producen un punto de inflexión acerca de plasmar la motivación de la sentencia en su redacción ${ }^{57}$, y tal razonamiento motivador debe dar como consecuencia lógica una decisión congruente.

\footnotetext{
${ }^{56} \mathrm{El}$ art. 218.1 lo regula como un aspecto de la congruencia referido a las sentencias: "harán las declaraciones que aquéllas (las pretensiones de las partes) exijan, condenando o absolviendo al demandado y decidiendo todos los puntos litigiosos que hayan sido objeto del debate"

${ }^{57}$ Murillo Villar, A., La motivación ... cit. p. 23, 24.
} 


\subsubsection{Appellatio}

Un cambio sustancial que se opera en este sistema procesal respecto al anterior ordo iudiciorum privatorum será la incorporación de la appellatio como remedio en general que también afecta a las sentencias incongruentes, (D. 49. 1. 1). Esta posibilidad cambia el criterio de responsabilidad del juez que queda exonerado de responder ante esta circunstancia, por litem suam facere.

Era obligación del magistrado de instancia plasmar por escrito las razones alegadas por el apelante, litterae dimisioriae, para enviar al órgano que ha de resolver. Se repetía el iudicium y el apelante podía añadir nuevos hechos y pruebas para fundamentar su recurso C. 7. 62. 32 (a. 440). El adversario debe responder con todas sus razones C. 7. 62.39 (a. 530).

Sin embargo, en D. 49. 8. 1. 1. se indica que en caso de error de cálculo en la sentencia, no hay motivo de apelación: Item si calculi error in sententia esse dicatur, appellare necesse non est; y continua con un ejemplo, si el juez hubiere fallado así: «constando que Ticio le debe á Seyo cincuenta por tal concepto, y además veinticinco por tal otro concepto, condeno por lo tanto en ciento a Lucio Ticio á favor de Seyo»; porque como hay error de computación, no es necesario apelar, y se corrige sin, ni siquiera, plantear la apelación, en una suerte de antecedente del recurso de aclaración. Pero si el juez de esta cuestión hubiere confirmado la sentencia a cien, pero porque hubo otra partida de veinticinco, ha lugar la apelación ${ }^{58}$, debiendo distinguir si es un mero error de cálculo, no apelable, o una extrapetición, si se ha incluido otra partida de veinticinco por algún otro concepto, que aquí sí que puede apelar.

\section{BREVE SINOPSIS DE SU EVOLUCIÓN POSTERIOR.}

En la Recepción del Derecho romano justinianeo en España también encontramos referencias a la congruencia en el Fuero Juzgo, en el Fuero Real, en el Espéculo, en las Partidas, así como en la Nueva y la Novísima Recopilación.

\subsection{Fuero Juzgo}

El Fuero Juzgo Libro II, De los jueces e de lo que iudgan Título I, capítulo XXIX Que el iuez debe dar razon de quantol demandaren contiene una referencia genérica a este respecto.

El iuez, si alguno le demanda razon delo que iudgó antel sennor de la cibdad, ó ante otro iuez ante qui mandare el rey, dévele responder. ${ }^{59}$

Pero sobre qué debe responder o cómo hacerlo no está referido. Más clara es la redacción del Fuero Real que vemos a continuación.

\footnotetext{
${ }^{58}$ Es curioso advertir las semejanzas entre lo expresado en los textos romanos y el remedio procesal de la aclaración de sentencias, que no recurso de apelación a tenor del Artículo 267. LOPJ 6/1985, de 1 de julio cuando prescribe en su punto 1. Los tribunales no podrán variar las resoluciones que pronuncien después de firmadas, pero sí aclarar algún concepto oscuro y rectificar cualquier error material de que adolezcan... 3. Los errores materiales manifiestos y los aritméticos en que incurran las resoluciones judiciales podrán ser rectificados en cualquier momento.

59 Sigue: E si el pelyto viniere antel rey, los iuezes qui mandare el rey, deven terminar el pleyto sin el obispo, e sin los otros iuezes. E si el pleito es comenzado, o acbado antel obispo, o ante qualquier iuez, e alguna delas partes troxiere a otro mandado del rey, elque iudgó el pleito, devel responder ante aquel iuez, que establesciera el rey; que si iudgó tuerto, que sea penado segund la ley; e si el otro se querello con tuerto, quel faga emienda segund la ley.
} 


\subsection{Fuero Real}

En el Fuero Real 2. 13. 2, manda que el juez sentencie sobre lo que se le demanda y no sobre otra cosa, en lo que resulta una descripción de coherencia: el juez debe dar su juicio sobre la demanda y no sobre otra cosa.

F.R. 2. 13. 2 "Como el Juez debe dar la sentencia sobre la demanda, é no sobre otra cosa. Despues que las razones fueren acabadas, de guisa que mas no pueden decir las Partes en el Juicio, el Alcalde dé la sentencia sobre aquello que fue la demanda, è no sobre otra cosa: è déla la mas cierta que pudiere, è no dubdosa, è de guisa que dé el Alcalde aquel contra quien fuere la demanda por quito, ó por vencido..."

Ciertamente, se describe la congruencia en cuanto a que se debe sentenciar sobre lo que se solicita y, es más, añade referencias a la claridad en el juicio como nota unida a la congruencia, nota que seguirá acompañando a la redacción de los preceptos sobre ésta ${ }^{60}$.

\subsection{Espéculo}

También encontramos referencias en el Espéculo, texto que, aunque no llegó a tener vigencia por inacabado, es muy similar a las tres primeras Partidas y al Fuero Real, así, en su Libro V, Tit. XIII Ley VII se describe cuando el juez da más o menos de lo que deben o dan una cosa por otra.

Yerran a las vegadas los judgadores en dar los juyzios, bien asi como los fisicos en dar las melezinas. Ca a las vezes dan menos o mas de lo que deven, e cuy dan dar una cosa, e dan otra. E esto otrosí fazen los judgadores en sus juyzios. Ca vegadas y a que añaden o minguan en ellos, o judgan dotra manera, que non pertenesce al pleito. $\cdot$ E por ende queremos dezir en quantas maneras non vale el juyzio por razon del judgador, sil da como non deve.

En este caso se prohíbe que el fallo sea diferente a las pretensiones de las partes y demás actos deducidos en juicio, y de hacerse resultará no válido.

\subsection{Partidas}

Será en la Tercera Partida, Tit. XXII Ley XVI, que versa sobre Cómo non debe valer el juicio que diere el judgador sobre cosa que non fue demandada ante él ${ }^{61}$, la que más se aproxime al concepto de congruencia, y la que tendrá repercusión jurisprudencial mucho más adelante: "Afincadamente debe catar el judgador qué cosa es aquella sobre que contienden las partes ante él en juicio, ...et entonce debe dar juicio sobre aquella cosa”. Y continúa dando dos ejemplos

\footnotetext{
${ }^{60}$ Ya está reseñada en el Fuero Juzgo Libro I, ley VI; en el Fuero Real F.R. 2. 13. 2, cuando dice que no debe ser dudosa. Veremos también alusiones en P. III, Tit. XII, ley V: "E deue fer dictado el juyzio por buenas palabras, e apuestas que lo puedan bien entender sin dubda ninguna". En la Codificación el artículo 61 de la Ley de Enjuiciamiento Civil de 1855 describe de forma muy somera la claridad; también se refiere a ello el artículo 359 de la Ley de Enjuiciamiento Civil de 1881 que califica las sentencias de claras, precisas, y congruentes.

${ }^{61}$ MANReSa y NAVARro, Comentarios á la última ley de enjuiciamiento civil español (Vol. 1), Impr. y Encuadernación de A. de J. Lozano, 1891, referido a la Ley de Enjuiciamiento Civil del 1855, considera que se aplicó este precepto de las Partidas hasta esa ley sin ruptura, y en ella al no hacerse referencia expresa a la congruencia, ésta se alegaba por el juego de los artículos 1012 y 1013 del mismo cuerpo legal.
} 
en los que no debe valer el juicio, si se demanda sobre casas o bestias u otras cosas que no están en la demanda, o si se pleitea sobre propiedad y se resuelve sobre posesión ${ }^{62}$.

Al mismo tiempo en esta Ley XVI, se indica que la manera en que se pide tiene transcendencia, puesto que "asi como fue fecha antél (juez) la demanda en general, en aquella mesma manera debe él dar el juicio" "63.

También encontramos en esta Ley la coherencia cuando, aún sin ser determinada la petición, si ésta es determinable, el fallo podrá ser válido; por el contrario, si en el juicio no se señala la cosa o cantidad cierta sobre la que se resuelve, el fallo no será efectivo ${ }^{64}$.

Respecto a las posibles dudas del juzgador para proferir su sentencia, sabemos de las soluciones que se dan en Derecho romano clásico. En esta tercera Partida, Tit.XXII, ley XI, Que deuen fazer los judgadores quando dudaren en como deuen dar juyzio, varían. En ella se prescribe que primero se pregunte "alos omes sabidores... e mostrarles todo el hecho, asi como passo ante ellos"; si con su concurrencia se aclara la duda se sentencia, pero si no se puede aclarar lo preguntado, enviará todo al Rey, aunque antes debe leerlo ante las partes y razonar la petición. El Rey puede sentenciar o indicar al juzgador como debe sentenciar. Pero ningún juzgador puede hacer esto por excusarse del trabajo, ni por alargar el pleito, ni por miedo, ni por amor o desamor a alguna de las partes sino porque debe escoger el derecho apropiado. Si lo hace de otra manera puede recibir condena penal del Rey.

\subsection{Nueva y Novísima Recopilación}

En la Nueva Recopilación Libro 4, título 17, ley 10, se insiste en que en los pleitos deben ser sobre los que las partes quieren decir y razonar. Y explica como si la demanda no se hizo en el escrito primero, los jueces deben dar "los pleytos por ningunos", e incluso se insiste, si una parte quiere que se trate algo y la otra no quiere, aunque se le solicite varias veces, si mantiene su negativa no puede condenarse por ese extremo, se debe tener "el pleyto por ninguno", y el juez condenado en costas. En la Novísima Recopilación libro 11, titulo 16, Ley 2, recoge el mismo contenido del texto anterior como ella misma indica ${ }^{65}$.

62 "ca si fuere fecha demanda antél sobre un campo ó sobre una viña, et él quisiere dar juicio sobre casas, ó bestias ó sobre otras cosas que non pertenesciesen á la demanda, non debe valer tal juicio: eso mesmo decimos que serie si la demanda tan solamente fuese fecha sobre el señorio de la cosa et él judgase sobre la posesión ". Este segundo ejemplo nos recuerda al recogido en C. 7. 48. 3.

${ }^{63}$ En este caso el ejemplo tiene relación con la determinación del objeto, así si no se determinó en la petición el juez no puede hacerlo en su fallo: "si el demandador demandase antel juez á otri caballo ó siervo quel mandara ó le prometiera, non nombrandol nin señalando ciertamente quál, et el juez diese despues juicio contra el demandado que diese al demandador fulan siervo señalandol por su nombre, ó fulan caballo señalandol por su color ó por sus faciones, tal juicio como este non serie valedero"

64 "Otrosi decimos que quando los judgadores non dicen ciertamente en su juicio la cosa ó la contia de que condenan ó quitan al demandado, mas dicen así: mando quel demandado pague ó entregue á fulan lo quel demndó ante mí, ó condénolo en la demanda que fue fecha contra él, ó quítolo della, ó tengo por bien que non dé lo quel demanda, ó posiere en su juicio otras palabras semejantes destas, por las quales se puede ciertamente entender que el demandado es quito ó vencido por jucio de la demanda, en tal razón como esta si fuere fallado escripto en las actas la cosa ó la contia sobre la contienda, que entonce el juicio que fuese dado en alguna destas maneras sobre ella, serie valedero. Mas si en las actas que pasaron antel judgador non se fallase cierta demanda, tal juicio en que non nombraba señaladamente la cosa ó la contia sobre que se daba, non serie valedero”.

${ }^{65}$ Novísima Recopilación libro 11, tit. 16, Ley 2, "Acaesce muchas veces que, desque los pleytos son contestados, y traidos testigos, y razonado en los pleytos de todo lo que las partes quieren decir y razonar, y concluso el pleyto para dar sentencia, y á las veces dada, estando el pleyto en apelación ante los Superiores, si se halla, que la demanda no fué dada en escrito, hallándola asentada en el proceso, ó que no está bien formada como los Derechos mandan ,ó 


\subsection{Codificación en las Leyes de Enjuiciamiento Civil.}

Si nos referimos a antecedentes más próximos, ya en la Codificación, en el artículo 61 de la Ley de Enjuiciamiento Civil de 1855 se describe de forma muy somera la claridad (siempre muy unido al concepto de congruencia) pero no la congruencia misma, y así dice este artículo que las sentencias deben ser claras y precisas, declarando o condenando o absolviendo de la demanda ${ }^{66}$.

Más adelante en el artículo 359 de la Ley de Enjuiciamiento Civil de 1881 recoge un precepto completo referido a que las sentencias sean claras, precisas, y congruentes con las demandas y con las demás pretensiones deducidas oportunamente en el pleito, y a la obligación de decidir todos los puntos litigiosos, en caso de que haya varios demandantes se responderá a cada uno de ellos y por separado. Cuando se trata del modo y forma en que han de dictarse las resoluciones judiciales, se dice en él

Art. 359: Las sentencias deben ser claras, precisas y congruentes con las demandas y con las demás pretensiones deducidas oportunamente en el pleito, haciendo las declaraciones que estas exijan, condenando o absolviendo al demandado, y decidiendo todos los puntos litigiosos que hayan sido objeto del debate. Cuando estos hubieren sido varios, se hará con la debida separación el pronunciamiento correspondiente a cada uno de ellos.

Tanto el actual artículo 218.1 de la Ley de Enjuiciamiento del año 2000 como el anterior art. 359, se ven influidos por lo que supone la aplicación del 120.3 de la Constitución española de 1978, que cuando habla de la publicidad en las actuaciones judiciales eleva a norma constitucional la obligación de motivar las sentencias, artículo 120.3 CE. Pero en lo que atañe a la coherencia de las sentencias no hay divergencias sustanciales entre las normas procesales del 218.1 y el anterior 359 .

\section{REFERENCIA A LA CONSTITUCIÓN ESPAÑOLA dE 1978}

Que la coherencia de las peticiones y el fallo, es esencial viene amparado en que está relacionada con el derecho fundamental del art. 24 de la tutela judicial efectiva como bien se

desfallesce el pedimento, ó al guna de las otras cosas que en ella debían de ser puestas, ó otras que son de la solemnidad y substancia de la órden de los juicios, por lo qual suelen los Jueces dar los pleytos por ningunos, y las sentencias que por ellos son, dadas, y así los Pleytos se alargan, de que viene grande daño á las partes: por ende establecemos, así en los pleytos civiles como criminales, así en primera instancia como en segunda ó tercera, que si la demanda ó acusacion paresciere asentada en el proceso, aunque no sea dada por la parte en escrito, ó faltare en la demanda el pedimento, ó alguna de las cosas que en la demanda deben ser puestas segun la sutileza del Derecho,ó que; no se haya fecho juramento de calumnia, estando pedido por la parte una vez solamente, ó que la sentencia no fué leida por el Alcalde, ó que desfallescen las otras solemnidades y substancias de la órden, de los juicios que los Derechos mandan, ó alguna dellas, conteniéndose todavía en la demanda de la cosa que el demandador entendió demandar, o el acusador pedir, seyendo hallada y probada la verdad del fecho por el proceso, en qualquier de las instancias que se viere, sobre que se pueda dar cierta sentencia; que los Jueces que conoscieren de los pleytós, y los hobieren de librar, los determinen y juzguen segun la verdad que hallaren probada en los tales pleytos, y las sentencias, que en ellós dieren, por las razones dichas no dexen de ser valederas: pero si el demandado, seyendo llamado antes que vaya el pleyto adelante, pidiere, que el demandador dé su demanda por escrito, que quede en albedrío de Juez para lo mandar, si viere que conviene que se faga así: y ansimismo, que si las cosas que fueren de substancia del juicio, y la parte pidiere, declarándolas, que la otra parte las guarde, y no quisiere, seyéndole mandado, y lo mismo en no jurar de calumnia, seyéndole pedido y mandado dos veces, que entónces, sentenciando el Juez sin se facer lo suso dicho, sea habido el pleyto por ninguno, y el Juez. condenado en costas." (ley. 10. Tit. 17. Lib. 4. R.)

${ }^{66}$ A este respecto es curioso que MANRESA op, cit, p. 166, nota 1, indica que cuando se aduce falta de congruencia, se deben invocar la Partidas y no el artículo 61.1, en el pertinente recurso de casación, al no estar expresamente regulado en el texto legal del 1855 . 
deduce de una Sentencia del Tribunal Constitucional 166/1992 de 26 de octubre, cuando refiere que puede producirse indefensión si el juez modifica o altera los términos del debate procesal. Esto sucede cuando el órgano judicial por iniciativa propia, se pronuncia sobre pretensiones que no han sido promovidas por ninguna de las partes que suponen menoscabo del derecho de defensa contradictoria. En el proceso civil, también estará íntimamente unido, con el principio dispositivo y de aportación de parte, por cuanto en este caso sólo se debe resolver aquello que las partes plantean al juzgador, y son ellas las que definen los términos del proceso, libres por tanto para determinar su reclamación. El juez no podrá salirse de estos confines en su resolución ${ }^{67}$. Esta línea jurisprudencial no se rompe hasta nuestros días, siendo múltiple la Jurisprudencia tanto Constitucional como del Tribunal Supremo que define la congruencia ${ }^{68}$

\section{CONCLUSIONES}

En Derecho romano ya encontramos antecedentes de lo que puede ser la congruencia procesal en el procedimiento formulario del ordo iudiciorum privatorum. Las partes procesales y el magistrado fijan, al final de la fase in iure, los términos de la fórmula, deciden cual es la cuestión debatida y que hechos deben ser probados, lo cual tendrá su reflejo en la sentencia. El iudex deberá decidir como consecuencia de los hechos probados, siendo responsable directo de su decisión. En cambio, en la cognitio extra ordinem el juez al dictar sentencia es más versátil y sus sentencias se adaptan mucho mejor a las pretensiones iniciales, hasta el punto en que podemos encontrar casos de ultra, extra e infra petición con adaptabilidad del fallo a las demandas de parte, construyéndose un concepto de congruencia próximo al que se maneja en nuestro derecho positivo.

En cuanto a la responsabilidad del juez por dictar una resolución incongruente es muy diversa en el ordo iudiciorum privatorum y en la cognitio extra ordinem, pero es significativo que este último proceso sea más parecido al proceso civil actual. El juez del procedimiento formulario si dicta una resolución incongruente, debe subrogarse en la posición de la parte perjudicada, por aplicación del cuasidelito litem suam facere, resultando afectado en su propio patrimonio. Sin embargo, la existencia de apelación en la cognitio extra ordinem y en el proceso civil actual, hace que el juez no sea responsable de los casos de falta de congruencia, cuando esta no sea dolosa.

${ }^{67}$ TJUE 3 de octubre 2013. Congruencia en determinados aspectos de derecho de consumo en relación con la Directiva 1999/44 sobre renta y garantía de bienes de consumo en cláusulas abusivas indica que no es preciso que el fallo se ajuste al suplico de la demanda TS 241/2013 de 9 de mayo.

${ }^{68}$ La Sentencia del TC 135/2002 de 3 de junio, posterior a la Ley de Enjuiciamiento Civil del 2000 en su FJ 3 refiere múltiple jurisprudencia al respecto: "No está de más volver aquí sobre la consolidada jurisprudencia del Tribunal Constitucional respecto a la incongruencia, sintetizada y resumida en el F. 2 de la STC 15/1999, de 22 de febrero, fundamento repetido en el F. 3 de la STC 124/2000, de 16 de mayo.En ambos lugares se nos recuerda que este Tribunal ha declarado reiteradamente que el vicio de incongruencia, entendido como desajuste entre el fallo judicial y los términos en que las partes formularon sus pretensiones, concediendo más o menos o cosa distinta de lo pedido, puede entrañar una vulneración del principio de contradicción, lesiva del derecho a la tutela judicial, siempre y cuando la desviación sea de tal naturaleza que suponga una sustancial modificación de los términos en que discurrió la controversia procesal (SSTC 177/1985, de 18 de diciembre; 191/1987, de 1 de diciembre ; 88/1992, de 8 de junio ; 369/1993, de 13 de diciembre ; 172/1994, de 7 de junio ; 311/1994, de 21 de noviembre; 111/1997, de 3 de junio ; y 220/1997, de 4 de diciembre). El juicio sobre la congruencia de la resolución judicial presupone la confrontación entre su parte dispositiva y el objeto del proceso delimitado por referencia a sus elementos subjetivos -partes- y objetivos -causa de pedir y «petitum»-. Ciñéndonos a estos últimos la adecuación debe extenderse tanto al resultado que el litigante pretende obtener como a los hechos que sustentan la pretensión y al fundamento jurídico que la nutre, sin que las resoluciones judiciales puedan modificar la «causa petendi» alterando de oficio la acción ejercitada, pues se habrían dictado sin oportunidad de debate ni de defensa sobre las nuevas posiciones en que el órgano judicial sitúa el «thema decidendi»". 
Se constata a lo largo del trabajo cómo la congruencia de la sentencia, pese a ser referida en diferentes textos de Derecho romano, y en la Recepción, no adquiere una formulación expresa en derecho positivo hasta el artículo 359 de la Ley de Enjuiciamiento Civil de 1881, llegando en la actualidad a tener reflejo en el Texto Constitucional de 1978 y en la vigente Ley 1/2000, de 7 de enero, de Enjuiciamiento Civil.

\section{REFERENCIAS}

BIONDI, B., Intorno alla rominità del processo civile moderno, BIDR 42, Roma, 1934.

CALAMANDREI, P., La casación civil, T. I, Historia y Legislaciones, Vol. I trad. esp. Buenos Aires, Librería el Foro, 1961.

COSTA, E., Profilo storico del processo civile romano, Roma, Athenaeum, 1948.

CREMADES, i., y Paricio, J., La responsabilidad del juez en el Derecho romano clásico, en AHDE 54, 1984.

DE LA OLIVA SANTOS, A., Sobre la congruencia de la sentencia civil. Sobre la congruencia de la sentencia civil y penal. Derecho y proceso. Estudios jurídicos en honor del Prof. A. Martínez Bernal, Murcia, Universidad de Murcia, 1980;

DE MARTINO, F., Litem suam facere, Bulletino dell'Istituto di Diritto Romano "Vittorio Scialoja", 1988.

D’ORS, A., Litem suam facere, Roma, Pontificia Universitas Lateranensis. 1982.

FUENTESECA, M., El enigmático significado de litem suam facere. IVRA: rivista internazionale di diritto romano e antico, $\mathrm{n}^{\circ}$ 63, Napoli, 2015.

GUARINO, A., Diritto privato romano, $8^{\circ}$ ed. Napoli, Jovene, 1988.

GUASP - ARAGONESES, J., Derecho Procesal Civil, T. I. Madrid, Thomson, 2005.

GIUSTO. Per una storia del litem suam facere. Studia et documenta historiae et iuris, $\mathrm{n}^{\circ}$ 71. Città del Vaticano, 2005.

KASER, M., Derecho romano privado, Madrid, ed. Reus, trad. esp., $2^{\circ}$ ed, 1982.

LLOBELL TUSET, J., Historia de la motivación de la sentencia canónica. Zaragoza, Edita Caja de ahorros y Mote de Piedad de Zaragoza, Aragón y Rioja, 1985.

MANRESA Y NAVARRO, Comentarios á la última ley de enjuiciamiento civil español (Vol. 1), Impr. y Encuadernación de A. de J. Lozano, 1891.

MURGa Gener, J. L., Derecho Romano Clásico, II. El Proceso, $2^{\circ}$ ed. Zaragoza, Prensas Universitarias de Zaragoza, 1983.

MURILLO VILLAR, A. Antecedentes históricos de la obligación de motivar las decisiones judiciales en el Derecho español. Teoría e storia del diritto privato, 2012

MURILLO VILLAR, A. La motivación de la sentencia en el proceso civil romano. Cuadernos de Historia del Derecho $\mathrm{n}^{\mathrm{o}}$ 2, 11-46. Madrid, Editorial Complutense, 1995.

MURILLO VILLAR, A., ¿Para qué sirve el Derecho romano? Razones que justifican su docencia e investigación en el siglo XXI, Santiago de Compostela, Andavira, 2018.

ORTELLS RAMOS, M., Derecho procesal civil, Navarra, Aranzadi, 2017. 
ORTELLS RAMOS, M., Origen histórico del deber de motivar las sentencias, Revista de Derecho Procesal Iberoamericana. 1977, nº 4, p. 899 y ss.

PANERO GUTIÉRREZ, R., Derecho romano, Valencia, Tirant lo Blanch, 2008.

PARICIO, J., "Iurare sibi non liquere", en Atti del III Seminario romanistico gardesano (Milán, 1988), p. 414-416.

PARICIO, J., Sobre la administración de la justicia en Roma: los juramentos de los jueces privados, Madrid, Civitas, 1987.

PRIETO CASTRO Y FERRÁNDIZ, L., "El principio de congruencia como limitación de las facultades de la jurisdicción”, Trabajos y orientaciones de Derecho procesal, Revista de Derecho privado. Barcelona, 1969.

PUGLIESE, G., Istituzioni di Diritto romano, Padova, Sintesi, 1986.

ROBLES REYES, J. R., La competencia jurisdiccional y judicial en Roma. Murcia. Ed. Universidad de Murcia, 2003.

RODRÍGUEZ AGUILERA, C, La sentencia, Barcelona, Bosch, 1974.

Savigny, M. F. C., Sistema del Derecho romano actual., trad. esp. $2^{\circ}$ ed., Tomo V-VI, reimp. Facs., Madrid, Góngora, 2004.

SCAEVOLA In margine al litem suam facere in età postclassica e giustinianea. SDHI. Studia et documenta historiae et iuris, $n^{\circ} 79,2013$.

SCIAlOJA, V., Procedura civile romana. Esercizio e difesa dei diritti, IVS. Collezione di scritti giuridici, XV Milano- Roma, 1936.

SERRA DOMINGUEZ, M., "Incongruencia civil y penal" en Estudios de Derecho Procesal, Barcelona, Ariel, 1969

TALAMANCA, M., Instituzioni di Diritto romano. Milano, Giuffrè, 1990.

TALAMANCA, m., s.v. Processo civile (diritto romano) en Enc. dir XXXVI, Milano, Giuffré, 1987.

Recebido em: 25 set. 2019.

Aceito em: 17 mar. 2020. 